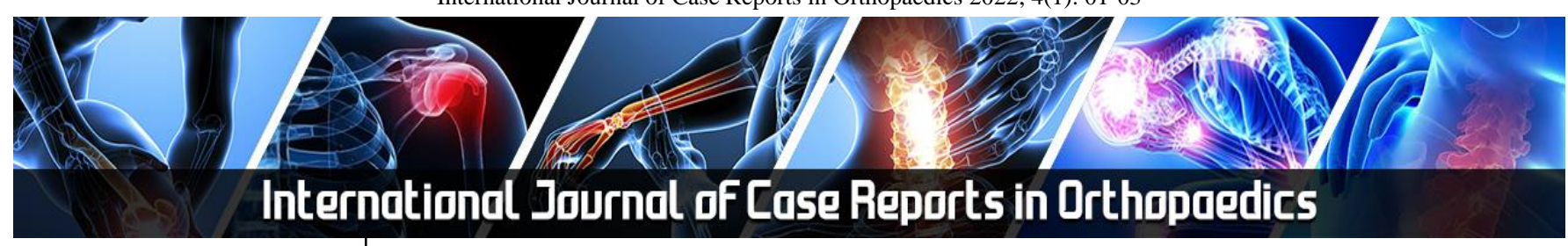

E-ISSN: 2707-8353 P-ISSN: 2707-8345 IJCRO 2022; 4(1): 01-03 Received: 21-10-2021 Accepted: 03-12-2021

Mobeen Khalid Qureshi MBChB, M.Sc., MRCS, Haslingden Rd, Blackburn BB2 3HH, United Kingdom

Qaisar Akhlaq Choudry MBChB, M.Sc., MRCS, Haslingden Rd, Blackburn BB2 3HH, United Kingdom
Corresponding Author: Mobeen Khalid Qureshi MBChB, M.Sc., MRCS, Haslingden Rd, Blackburn BB2 3HH, United Kingdom

\section{Low energy knee dislocation with neurovascular compromise in a patient with a high body mass index}

\author{
Mobeen Khalid Qureshi and Qaisar Akhlaq Choudhry
}

DOI: https://doi.org/10.22271/27078345.2022.v4.i1a.84

\begin{abstract}
We present a case of a 54-year-old patient with high body mass index (BMI) who presented with a traumatic knee dislocation with an associated popliteal artery occlusion after the patient's partner fell onto the affected patients' leg. This led to the patient requiring an urgent reduction in the emergency department (ED), followed by external fixation in theatre with popliteal artery bypass. This case highlights the importance of early recognition of vascular compromise and early reduction in the ED followed by relevant imaging.
\end{abstract}

Keywords: Body mass index, Low energy knee, serious injuries

\section{Introduction}

Knee dislocations are rare but serious injuries. They pose significant challenges in assessment and management. They are usually associated with high energy trauma. There is an increase in incidence of knee dislocation with low energy trauma in patients with a high BMI. We present a case report of patient with a BMI of 46 with low energy knee dislocation associated with common peroneal palsy and popliteal artery injury. These injuries can be limb threatening and necessitate detailed and serial examination of the affected limb with a high index of suspicion for a neurovascular injury. Popliteal artery injury is reported to occur in $7 \%-15 \%$ of knee dislocations ${ }^{[1]}$. It can occur in the form of occlusion, transection or intimal injury. It is uniquely susceptible to injury due to its ligamentous fixation and anatomical relationships to the tibia, femur and knee joint structures ${ }^{[2]}$.

\section{Case presentation}

A 54-year-old lady with a high BMI presented after her partner tripped in the garden and fell onto her, causing her to fall with all her weight on her right knee, the injury occurred at approximately 15:00 and the patient was bought to the Emergency Department. She was noted to be orientated to time and place and able to communicate with no problems. She weighed 146 kilograms in weight and her BMI was calculated to be 46. On examination of her right lower limb no pedal pulse was palpable and no flow was detectable using a handheld Doppler. She had no sensation in the deep peroneal nerve and superficial peroneal nerve distributions. Complete foot drop was noted, as well a cold pale foot with poor capillary refill.

\section{Investigations}

Initial right knee plain radiographs revealed a posterior knee dislocation (Figure 1 and 2). The patient was given conscious sedation in ED and a closed reduction by the Trauma \& Orthopaedic team was performed (Figure 3 and 4). This was challenging due to her weight and size, requiring multiple personnel, following reduction no distal pulses were noted on palpation or Doppler. The right foot remained pale. The knee was immobilised in a plaster of Paris black slab to allow transfer for an urgent CT angiogram of the right lower limb. The CT scan showed a reduced knee joint, however there was a $9 \mathrm{~cm}$ popliteal artery occlusion with thrombus (Figure 5).

\section{Treatment}

Multiple disciplinary team discussion with radiologists, anaesthetists and vascular surgeons. The patient was taken immediately to theatre where the right knee was examined under anaesthetic and noted be grossly unstable with gross laxity noted and suspected rupture of the medial collateral ligament, posterior cruciate and anterior cruciate ligaments. 
An anterior bridging external fixator to the right lower limb was applied, with two antero-lateral femoral pins and two antero-medial tibial pins. The patient then immediately in the same sitting underwent a femoral-popliteal bypass of the right lower limb. Intra-operatively it was noted that all muscle groups above and below the knee joint were bruised and the calf muscles were noted to be tense and swollen. Gross varicosities were noted in the thigh and below the knee joint in the distribution of the long saphenous vein. A patent distal superficial femoral artery with good flow was found with a patent below knee popliteal artery with good back bleeding from the run off vessels noted. Dissection down to the below knee popliteal artery was difficult due to a large haematoma and distorted anatomy due to the injury. Due to gross varicosities seen in the distribution of the long saphenous vein, it was deemed unsuitable for bypass. A $6 \mathrm{~mm}$ PTFE Dista-Flow graft was selected instead. The arteries above and below the knee were clamped. Arteriotomy was made, with good inflow noted and back bleeding from the below knee popliteal artery noted. The graft was tunnelled subfascially avoiding the haematoma area behind the knee. Prior to completion of the distal anastomosis, arteries and graft were flushed and a small thrombus was noted. Therefore, a small transverse incision was made in the graft near the proximal anastomosis for thrombectomy. Intraoperative Doppler showed a good biphasic/triphasic signal in the run off vessels. A closed fasciotomy was done in the right below knee medial compartment due to the tense calf.

\section{Outcome and Follow - Up}

Post-operatively the patient was comfortable, the foot was well perfused and pink. Sensation had improved but altered. Partial recovery of the foot drop was noted.

Patient was reviewed in the soft tissue knee multidisciplinary team meeting to discuss further management. Due to her BMI and her bypass in situ from the medial approach, no further surgical management was planned. The external fixator was adjusted and this was remained on for a period of 8 weeks. The patient has been further reviewed for soft tissue reconstruction; however this is not possible due to the graft and difficult arthroscopic approaches. The patient has been offered a Total Knee Replacement.

\section{Discussion}

Knee dislocations cause a significant challenge to both the patient and the orthopaedic team. The consequences of these ligamentous injuries can lead to severe disability and significant percentage of patients who suffer a knee dislocation are unable to return to their previous activity level ${ }^{[3]}$.

Knee dislocations in those with a high BMI usually occur when associated with minor trauma, rather than high energy trauma which is typically seen in knee dislocations ${ }^{[4]}$. In recent times there has been an increase in patients presenting with knee dislocation after low energy trauma ${ }^{[5]}$. Given these lower energy mechanisms of injury there has historically been a lower concern for neurovascular injury associated with them ${ }^{[6]}$. However, it has been reported in a study by Vaidya et al. who reported on 19 patient with high body mass indexes who sustained a low energy knee dislocation, that $7(44 \%)$ patients sustained a neurological injury and $5(27 \%)$ patients sustained a vascular injury ${ }^{[6]}$.
Vascular injuries can lead to a loss of limb if not dealt with promptly. Green et al. reported a delay of reperfusion of greater than eight hours can lead to an amputation in $85 \%$ of cases ${ }^{[7]}$. In a more recent study it was shown that $20 \%$ of knee dislocations that present with a vascular injury will require an amputation and in $80 \%$ of cases patients will still experience serious disability at two years ${ }^{[8]}$.

A large amount of research has been performed to assess the appropriate management of vascular injuries associated with knee dislocations ${ }^{[9,10,11,12]}$. The current gold standard is to clinically examine the patient including the evaluation of ankle-brachial index and to employ selective angiography if clinical examination is deemed to be abnormal. If an abnormality is found then on-table angiography or CTangiography is advocated. If a patient with a knee dislocation has no clinical abnormality after reduction then the patient should be admitted for serial examination with neurovascular checks regularly for a period of 48 hours ${ }^{[1]}$. In conclusion this case of knee dislocation resulting from low energy trauma emphasises the need for careful evaluation of the neurovascular status of the affected limb, immediate reduction and a prompt multi-disciplinary approach in managing the patient.

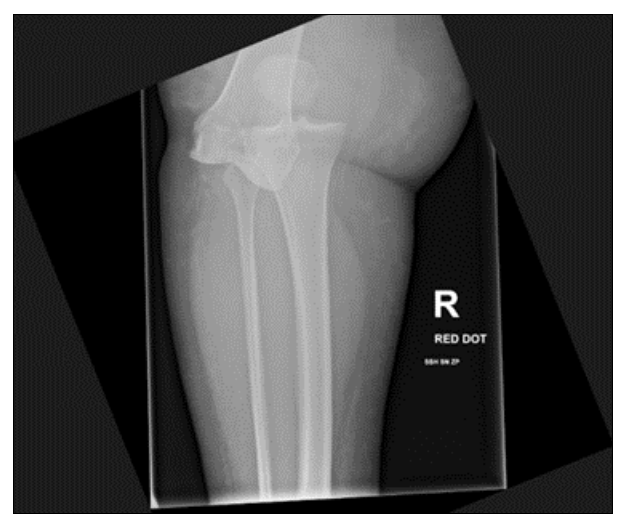

Fig 1: Anteroposterior knee radiograph pre reduction

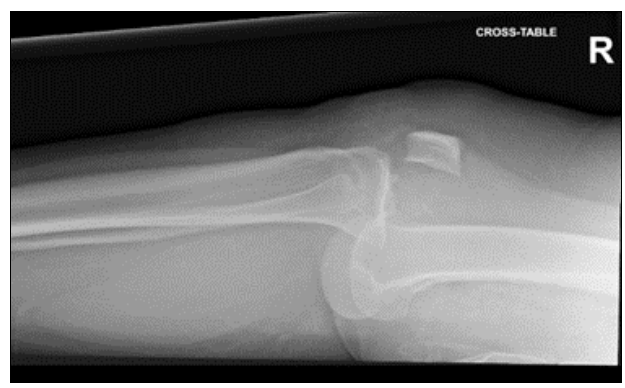

Fig 2: Lateral knee radiograph pre reduction

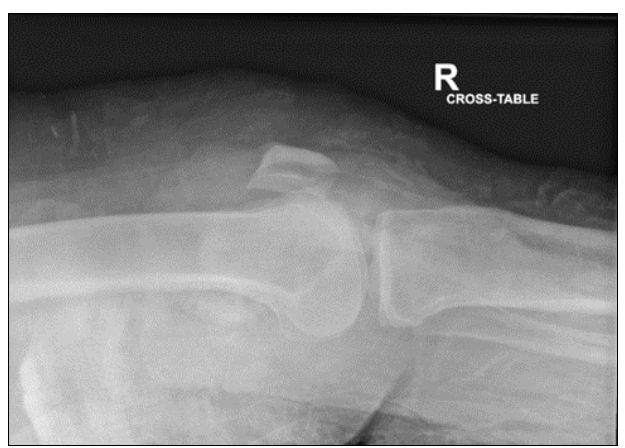

Fig 3: Lateral radiograph post reduction 


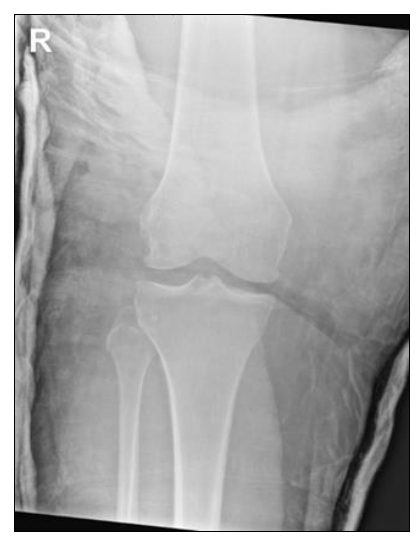

Fig 4: Anteroposterior radiograph post reduction

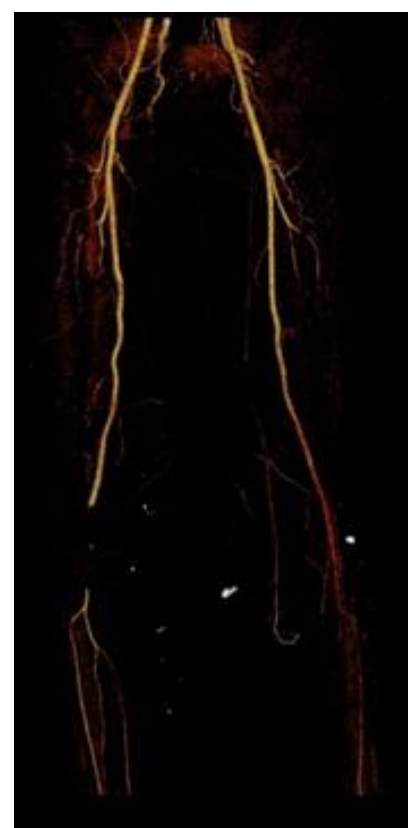

Fig 5: Computed tomography $(\mathrm{CT})$ angiogram 3D reconstruction displaying $9 \mathrm{~cm}$ popliteal artery obstruction

\section{References}

1. Stannard JP, Schreiner AJ. Vascular Injuries following Knee Dislocation. J Knee Surg. 2020. https://doi.org/10.1055/s-0040-1701210.

2. Karkos CD, Koudounas G, Giagtzidis IT, Mitka MA, Pliatsios I, Papazoglou KO. Traumatic Knee Dislocation and Popliteal Artery Injury: A Case Series. Ann Vasc Surg. 2018. https://doi.org/10.1016/j.avsg.2018.01.084.

3. Dedmond BT, Almekinders LC. Operative versus nonoperative treatment of knee dislocations: a metaanalysis. Am J Knee Surg. 2001.

4. Carr JB, Werner BC, Miller MD, Gwathmey FW. Knee Dislocation in the Morbidly Obese Patient. J Knee Surg. 2016. https://doi.org/10.1055/s-0036-1571432.

5. Kehoe A, Smith JE, Edwards A, Yates D, Lecky F. The changing face of major trauma in the UK. Emerg Med J. 2015;32:911-5. https://doi.org/10.1136/emermed2015-205265.

6. Vaidya R, Roth M, Nanavati D, Prince M, Sethi A. Low-velocity knee dislocations in obese and morbidly obese patients. Orthop J Sport Med. 2015. https://doi.org/10.1177/2325967115575719.
7. Green NE, Allen BL. Vascular injuries associated with dislocation of the knee. J Bone Jt Surg - Ser A. 1977. https://doi.org/10.2106/00004623-197759020-00017.

8. Patterson BM, Agel J, Swiontkowski MF, MacKenzie EJ, Bosse MJ, Kellam JF, et al. Knee dislocations with vascular injury: Outcomes in the Lower Extremity Assessment Project (LEAP) study. J Trauma - Inj Infect Crit Care. 2007.

https://doi.org/10.1097/TA.0b013e31806915a7.

9. Georgiadis AG, Mohammad FH, Mizerik KT, Nypaver TJ, Shepard AD. Changing presentation of knee dislocation and vascular injury from high-energy trauma to low-energy falls in the morbidly obese. J Vasc Surg. 2013. https://doi.org/10.1016/j.jvs.2012.11.067.

10. Wascher DC. High-velocity knee dislocation with vascular injury: Treatment principles. Clin Sports Med. 2000. https://doi.org/10.1016/S0278-5919(05)70218-0.

11. Nicandri GT, Chamberlain AM, Wahl CJ. Practical management of knee dislocations: A selective angiography protocol to detect limb-threatening vascular injuries. Clin J Sport Med. 2009. https://doi.org/10.1097/JSM.0b013e31819cd37a.

12. Mills WJ, Barei DP, McNair P. The value of the anklebrachial index for diagnosing arterial injury after knee dislocation: A prospective study. J Trauma - Inj Infect Crit Care. 2004.

https://doi.org/10.1097/01.TA.0000068995.63201.0B. 